Doi: 10.5212/PublicatioCi.Soc.v.21i1.0010

\title{
CONSUMO E CULTURAS HÍBRIDAS: UM ENSAIO EM LENTES ANTROPOLÓGICAS
}

\section{CONSUMPTION AND HYBRID CULTURES: AN ESSAY THROUGH ANTHROPOLOGICAL LENSES}

\author{
Gustavo Emanoel Pacheco Portes ${ }^{1}$ \\ Marcelo Engel Bronosky ${ }^{2}$
}

\begin{abstract}
RESUMO
Este artigo apresenta reflexão sobre a relação entre o fenômeno das culturas híbridas contemporâneas proposto por Canclini (2000) - relacionado ao multiculturalismo - e as dinâmicas de consumo com base em uma visão antropológica. Como pontua Levi-Strauss (1962), a antropologia passou, nas últimas décadas, por um deslocamento de perspectiva: ao passo que as culturas exóticas foram sendo conhecidas e perdendo seu exotismo, a disciplina deslocou seu foco do distante exótico desconhecido para o local desconhecido exótico. Passou a observar as cidades como universos de pesquisa e as relações sociais urbanas se tornaram objeto, entre as quais os fenômenos de consumo. Nesse sentido, o ensaio trata das relações entre culturas híbridas e consumo por uma ótica antropológica.
\end{abstract}

Palavras-chave: Cultura. Consumo. Antropologia do consumo.

\begin{abstract}
This article presents reflections on the relationship between the phenomenon of contemporary hybrid culture proposed by Canclini (2000) - related to multiculturalism - and the dynamics of consumption from an anthropological view. As Levi-Strauss points out (1962), anthropology underwent a shift of perspective in recent decades: while the exotic cultures became known and lost their exoticism, the discipline shifted its focus from the distant exotic unknown subject to the local but unknown and exotic subject. It started to observe the cities as universes of research and urban social relations became research topics, among which the phenomena of consumption. Therefore, the essay aims to discuss the relationship between consumption and hybrid cultures from an anthropological perspective.
\end{abstract}

Keywords: Culture. Consumption. Anthropology of consumption.

\footnotetext{
${ }^{1}$ Mestre em Ciências Sociais Aplicadas pelo Programa de Pós-Graduação em Ciências Sociais Aplicadas da Universidade Estadual de Ponta Grossa. ${ }^{2}$ Doutor em Ciências da Comunicação pela Universidade do Vale do Rio dos Sinos. Professor do curso de jornalismo da Universidade Estadual de Ponta Grossa e do Programa de mestrado em Jornalismo.
} 


\section{Introdução}

As fases históricas do desenvolvimento humano têm proporcionado problemáticas interessantes para as ciências sociais. Nas últimas décadas, em razão de consideráveis avanços tecnocientíficos, a estruturação da sociedade global parece estar se processando de forma cada vez mais complexa, fluida e heterogênea. Não há como negar que o processo de globalização contribui para essa fluidez.

Apesar de a globalização, como afirma Santos (2002), tender a certos níveis de massificação e homogeneização de pensamentos - referente às massas, às ideologias de senso comum que se propagam não mais em escala local ou regional, mas agora em escala global - também propicia, paradoxalmente, a mescla de movimentos, grupos e, sobretudo, culturas, gerando o que Canclini (2000) chama de culturas híbridas.

Paralelamente, a sociedade globalizada parece ter como principal motivador o consumo. Como indica Baudrillard (1995), as sociedades tornaram-se espaços de consumo e diversas lógicas existentes neles tendem a se processar em torno do consumo. Nas teorias sociológicas clássicas, especialmente de cunho marxista, o consumo parece estar ligado a dinâmicas estritamente racionais e econômicas. As análises clássicas ressaltavam o caráter racionalista em que os consumidores - em grande maioria o proletariado - conduziam suas lógicas de consumo. Nessas análises, esses consumidores (que ao mesmo tempo eram a força de produção da época) permaneciam continuamente afligidos pela exploração do capital e da mais valia. Seus escassos ganhos eram utilizados para sobrevivência e seu pequeno tempo livre dividido entre exprimidas horas de descanso e longas jornadas de trabalho, estas últimas vendidas como forma de multiplicar a renda. Em grande parte, eram responsáveis pelo sustento de suas famílias e casas, o que costumava ser dispendioso. Suas rendas eram utilizadas, portanto, da forma mais econômica e racional possível de maneira que cada parcela de recursos fosse sábia e eficazmente aplicada na sobrevivência.

A modernidade, e mais especificamente as mudanças contemporâneas das últimas décadas, moldaram esse perfil societário radicalmente. As teorias de rígidas estruturas de classes apresentadas pelos paradigmas clássicos passaram a disputar espaços com diversas outras perspectivas sobre a sociedade e sobre os fatos sociais, sobretudo relacionados à diversidade cultural e à horizontalização nas relações sociais. A mescla cultural cunhou novos sujeitos nascidos no interior de um mundo determinado pelo consumo. Consumo este que sofre por essa nova realidade tensões e influências, formando novos e amplos campos de investigação, notadamente aqueles orientados pelo olhar da antropologia urbana.

Nesse sentido, este artigo apresenta reflexão sobre as relações entre o consumo e as culturas híbridas com base em uma abordagem de vertente etnográfica. Procurou-se pensar a relação sob a visão de uma antropologia do consumo.

\section{Antropologia e consumo}

A antropologia social, oriunda da antropologia cultural, dedica-se ao estudo do homem como ser social e cultural. Evans-Pritchard (1978) ressalta que o seu objeto está vinculado às culturas e sociedades humanas. Nascida na Europa em fins do século XIX e difundida na América do Norte posteriormente, o principal foco da antropologia social - especialmente durante a primeira metade do século XX - permaneceu nas sociedades desconhecidas, nativas e exóticas.

Os fins que motivaram esses estudos foram principalmente os de cunho acadêmico/científico e de caráter imperialista. O conhecimento da cultura e sociabilidade de tribos e povos isolados e até então tidos como primitivos ${ }^{3}$ propiciava uma nova instrumentalização e a construção de métodos de dominação mais eficazes sobre esses povos pelos países centrais, especialmente a Inglaterra.

Durante as últimas décadas, uma mudança de perspectiva antropológica chegou ao ápice induzida pela extinção de nações indígenas e a proibição de pesquisas em certos povos.

Sob esse quadro, Levi-Strauss (1962, p. 21) apontou que "a antropologia corre o risco de tornar-se uma ciência sem objeto". Efetivamente essa

\footnotetext{
${ }^{3}$ Após a publicação de "A origem das espécies”, de Charles Darwin (1859) a antropologia cultural e a social adotaram perspectivas estritamente evolucionistas. Esse paradigma foi abandonado a partir do momento em que a cultura dos povos nativos passou a ser encarada mais como diferente do que primitiva. Cf. Magnani, 1996, p. 17.
} 
assertiva não se concretizou, porém um novo objeto da antropologia emergia em paralelo.

A antropologia, em parte, direciona nesse período seu olhar aos centros urbanos e à riqueza e liquidez das relações sociais e culturais lá processadas.

Nasce, portanto, a antropologia urbana e suas variáveis. Para complementação dessa descrição histórica, na década de 1960, enquanto as escolas europeias de antropologia ainda se dedicavam largamente a pesquisas em povos indígenas, a antropologia norte-americana - especialmente na Universidade de Chicago - direciona seus olhares às metrópoles e às relações lá processadas. Com a influência do que veio a ser chamada Escola de Chicago, a antropologia urbana consolidou-se como disciplina e passou a pesquisar diversas temáticas da urbe.

Autores como Marcel Mauss e Thorstein Veblen podem ser considerados pioneiros no estudo do consumo sob óticas antropológicas.

Posteriormente, com fundamento na base de estudos de Veblen, no final da década de 1970, Mary Douglas e Baron Isherwood publicaram, na Inglaterra, "O Mundo dos Bens: para uma antropologia do consumo", propondo novas lentes para as relações de consumo e um rico diálogo entre os estudos sobre consumo e antropologia urbana.

Na obra, Douglas e Isherwood (2004) apontam, sobretudo para as dimensões simbólicas e culturais do consumo e para a variedade de motivações que orientam o ato de consumir. Para Douglas e Isherwood (2004), o consumo é, em última análise, reflexo de julgamentos morais e valorativos culturalmente transmitidos; carregam significados sociais de grande importância.

O simbolismo apontado pelos autores está imerso em práticas que norteiam as próprias escolhas de consumo. Esse conceito advém de Pierre Bourdieu (1996). O autor apresenta o simbolismo imerso em estruturas de poder, qual seja um poder simbólico. "O poder simbólico é, com efeito, esse poder invisível, o qual só pode ser exercido com a cumplicidade daqueles que não querem saber que lhe estão sujeitos ou mesmo o exercem" (BOURDIEU, 1989, p. 8). O indivíduo contemporâneo, ao consumir, pretende ignorar a existência do simbolismo ao mesmo tempo em que o legitima pelo fim a que a prática do consumo se destina. Bourdieu apresenta o que considera economia dos bens simbólicos, afirmando que a lógica simbólica reifica e é incorporada no indivíduo a partir do habitus: disposições para sentir, pensar e agir sobre o simbolismo (Idem, 1996).

Para Douglas e Isherwood, segundo Leitão ${ }^{4}$, os bens simbolizam afeições, desejos; são instrumentos sociais, expressam e influenciam decisões culturais e são, portanto, os meios pelos quais o homem pode ser incluído em maior ou menor grau em um conjunto de relações sociais.

Dessa forma, a prática do consumo conduz-se para além do utilitarismo, agregando além do sentido simbólico, um significado ritual de passagem, inserção e/ou elevação sociocultural.

Nesse sentido, o diálogo entre a antropologia e o consumo permite explorar lógicas sociais que isoladamente as duas áreas não logram abarcar.

O foco central da antropologia do consumo está, portanto, em compreender as relações de consumo a partir da cultura e da sociabilidade de determinado recorte espaço-temporal.

Como pontua Barros (2007, p. 102):

O campo de estudo da antropologia do consumo se constitui, sobretudo a partir de uma crítica às interpretações apoiadas em teorias econômicas que reduziam o fenômeno do consumo à esfera do individuo, visto como um ser racional que realiza a compra procedendo a uma escolha que visa maximizar a utilidade.

As dinâmicas de consumo percebidas pelo olhar antropológico tendem a se aprofundar na causualística ulterior e na compreensão do próprio fenômeno de consumo por parte do consumidor. Complementarmente, por ser a etnografia o método de investigação corrente da antropologia, diversos estudos etnográficos sobre consumo têm aprofundado as possibilidades de debates e compreensão sobre a temática e sendo ainda explorados pela administração, pelo marketing e pela economia aplicada. Em razão de a técnica etnográfica ser composta por descrições densas e detalhadas dos fenômenos, como afirma Geertz (1989), as etnografias do consumo tendem a proporcionar um enriquecimento sobre a diversidade de razões e dinâmicas de consumo. Não se pretende, todavia, apresentar um determinante absoluto para a

\footnotetext{
${ }^{4}$ LEITÃO, D. "O mundo dos bens: para uma antropologia do consumo", por Débora Leitão. In: Comunidade Virtual de Antropologia. Disponível em: $<$ http://www.antropologia.com.br/res/res20.htm >. Acesso em jun. 2011.
} 
prática, mas permite-se uma compreensão mais profunda e subjetiva (a partir do indivíduo consumidor) dos fatores culturais e sociais que influenciam as escolhas de consumo e mesmo os que são criados por meio desses processos.

Na obra Antropologia do consumo: casos brasileiros (2007), Carmen Migueles apresenta algumas pesquisas recentes empreendidas no Brasil em antropologia do consumo. A autora informa que os critérios de análise de mercado utilizados correntemente no Brasil estão baseados em fórmulas estatísticas obsoletas que percebiam a sociedade apenas como uma sociedade de classes hierarquizada. A diversidade cultural e, sobretudo, essas dinâmicas de consumo simbólico e cultural eram desconhecidas e ignoradas nesses métodos. Isso ocorria em grande parte em razão da herança marxista e neomarxista presente na história do pensamento econômico e sociológico brasileiro, a exemplo de Florestan Fernandes e Celso Furtado.

Os estudos em antropologia do consumo, especificamente etnografias de consumo, tendem a avançar sobre esses critérios.

Nesse sentido, a antropologia do consumo permite a construção de uma ponte elucidativa relevante ao oferecer uma proposta mais ampla e, ao mesmo tempo, pontualmente sintonizada com as lógicas e as razões pelas quais o consumo contemporâneo se processa.

\section{Cultura, ideologia e hibridização cultural}

O debate sobre Cultura e suas definições não é recente. Prolonga-se por longos relatos históricos e diversas correntes de pensamento.

Geertz assinala que esse debate é interminável porque tem sido depositado sobre premissas distorcidas. Segundo o autor, por longo tempo, a intelectualidade tem debatido se a cultura é subjetiva ou objetiva (em relação ao grupo cultural pesquisado). Debater se a cultura é subjetiva ou objetiva para Geertz é conceber o debate "de forma totalmente errônea" (Geertz, 1989, p. 20).

O autor ressalta que a questão não se deve localizar na origem da cultura. "Uma vez que o comportamento humano é visto como ação simbólica (...) o problema se a cultura é uma conduta padronizada ou em estado da mente ou mesmo as duas coi- sas juntas, de alguma forma perde o sentido" (Idem, p. 20), porém "o que devemos indagar é qual a sua importância: o que está sendo transmitido com a sua ocorrência por meio da sua agência, seja ela um ridículo ou um desafio, uma ironia ou uma zanga, um deboche ou um orgulho" (Ibid., p. 20).

Há outras interpretações dissonantes, segundo o autor, como afirmar que a "cultura é uma realidade 'superorgânica' autocontida, com forças e propósitos em si mesma" (Ibid. p. 21) ou "alegar que ela consiste no padrão bruto de acontecimentos comportamentais que de fato observamos ocorrer em uma comunidade identificável” (Ibid). A primeira opção, segundo o autor, seria reificar a cultura, a segunda, reduzi-la.

Em outro aspecto e em oposição a essas duas premissas consideradas errôneas, o autor apresenta Goodenough ao afirmar que "a cultura [está localizada] na mente e no coração do homem" (Ibid.) o que, segundo afirma, não seria a melhor compreensão.

Além das variadas interpretações e dos conceitos sobre cultura, com base em outros intelectuais não apresentados neste ensaio, parece ser no próprio Geertz e em suas longas jornadas epistemológicas, majoritariamente baseadas em dados antropológicos empíricos, que um conceito menos volátil de cultura aparenta vir à tona. Para Geertz, enfim, a cultura é pública e impacta o conceito acerca da formação humana, isto é,

um conjunto de mecanismos simbólicos para controle do comportamento, fontes de informação extra-somáticas, a cultura fornece o vínculo entre o que os homens são intrinsecamente capazes de se tornar e o que eles realmente se tornam, um por um (GEERTZ, 1989, p. 64).

É, portanto, exterior e vinculativa ao cognoscível e às atitudes.

Tomando a questão por outro aspecto, pode-se inferir que a cultura seja fruto em algum grau ou pode ser mantida ideologicamente. Sobre esse ponto e sobre a ideologia em particular, Stuart Hall apresenta uma rica análise sobre a ótica althusseriana em ideologia. Uma noção verticalizada, antropologicamente distinta, contudo.

Para Hall (2009, p. 162), a ideologia em Althusser existe para garantir a manutenção de um sistema social. Um sistema hierarquizado em sua grande maioria em que a percepção da vida se dá 
pela percepção e a incorporação da ideologia. "As ideologias constituem estruturas de pensamento e avaliação do mundo - as ideias que as pessoas utilizam para compreender como o mundo social funciona, qual o seu lugar nele e o que devem fazer" (HALL, 2009, p. 163).

Em Althusser, como analisa, "a ideologia é uma prática" (Idem). É para Hall a materialização na forma de um existir passivo cotidiano, a partir da cognição inicial sobre o racionalizável vigente em determinada ordem social e cultural.

Se a cultura em Geertz (1989) é a soma desses mecanismos externos transmitidos ou adquiridos, socialmente funcionais e do conhecimento tácito acerca do simbólico e, em certo grau de inconsciência de sua valoração; aquela inferência se processa de forma a reconhecer nesse conhecimento tácito e posteriormente em sua manutenção materializada em práticas, como, em certo grau, a da ideologia proposta em Hall.

A ideologia pode ser percebida como amálgama entre o intrínseco e esses mecanismos simbólicos da cultura. Formam a base da cultura como sistema simbólico em maior ou menor grau.

Essa inferência não reduz em nenhum sentido o alcance da percepção geertziana de cultura. Ao contrário, uma vez que Hall expõe a ideologia em Althusser de forma ampla, oferece termos e percepções que permitem a multiplicidade de olhares sobre a ordem social.

Paralelamente e em algum sentido, a cultura manifesta-se de igual forma como prática a partir de uma ideologia incorporada.

Hall apresenta ainda nuances em sua obra Da Diáspora (2009) de que a contemporaneidade trouxe em seu bojo diversas problemáticas acerca da cultura, das transformações socioculturais e da teorização a esse respeito.

Em Culturas Híbridas - estratégias para entrar e sair da modernidade, Canclini (2000) apresenta uma problemática ampliadora. $\mathrm{O}$ autor discute as transformações culturais nas últimas décadas, especialmente na América Latina. Torna-se interessante pela mescla de debates empíricos e teóricos em um universo geográfico ainda considerado marginal.

Canclini discute em Culturas Híbridas (2000, p. 284), os efeitos da expansão urbana e as transformações culturais trazidas por essa expansão. Avalia as possibilidades teóricas de uma pós-modernidade na América Latina e relê algumas noções das ciências sociais sobre o "rótulo de culto popular" (Idem, p. 285).

Canclini (Ibid.P.) indica que a urbanização crescente na América Latina é umas causas da hibridização cultural:

(...) passamos de sociedades dispersas em milhares de comunidades rurais com culturas tradicionais, locais e homogêneas, com pouca comunicação com o resto de cada nação a uma trama majoritariamente urbana, em que se dispões de uma oferta simbólica heterogênea, renovada por uma constante interação do local com redes nacionais e transnacionais de comunicação.

O autor propõe que "as ideologias urbanas atribuíram a um aspecto da transformação, produzida pelo entrecruzamento de muitas forças da modernidade, a 'explicação' de seus nós e suas crises” (Ibid.). Desloca, assim, a questão ideológica para uma funcionalidade instrumental epistemológica e teórica, conquanto não the negue o poder transformador da realidade social e sua influência à base cultural.

Apresenta argumentos, como a quebra e mescla das coleções organizadas pelos sistemas culturais e a construção de uma heterogeneidade multicultural a partir de processos migratórios e do que considera trans e/ ou desterritorialização da cultura.

Canclini apresenta os exemplos de Tijuana e outras metrópoles mexicanas, em que símbolos monumentais de um passado cultural se fundiram a novas leituras e significações modernizantes, a exemplo das pinturas e do artesanato asteca e inca que se tornam objeto para fotos de turistas americanos em Tijuana, ou ainda as rádios em Los Angeles, que veiculam conteúdo em espanhol destinado ao público mexicano local. Esses fenômenos são a essência da hibridização cultural, essa mescla transfronteiras de culturas e proficuamente heterogênea em seu seio.

Em contrapartida, essa multiculturalização se processa em lógicas oblíquas, segundo Canclini. Em realidade, as culturas híbridas são fruto e ao mesmo tempo gestam poderes oblíquos. Além do fato de que "todas as artes se desenvolvem em relação com outras artes: o artesanato migra do campo para a cidade; os filmes, os vídeos e as canções que narram acontecimentos de um povo são intercambiados" (Ibid., p. 348), há ainda outros modos pelos quais 
essa obliquidade simbólica permite repensar as relações entre cultura e poder. "A busca de mediações, de vias diagonais para gerir os conflitos, dá às relações culturais um lugar preeminente no desenvolvimento político" (Ibid.) e, paralelamente, conduz a novas percepções de mercados culturais.

Essas culturas híbridas e suas ideologias abrem um vasto campo para a exploração antropológica, sobretudo para a antropologia do consumo. Novos grupos sociais e culturalmente distintos tendem a apresentar lógicas de consumo também distintas e específicas.

\section{Culturas híbridas e consumo}

Uma concepção clássica do consumo sugere que seus processos ocorrem por lógicas racionais e econômicas, como descrito anteriormente. A hierarquia das necessidades de Maslow (1975) é, sem dúvida, a clássica percepção dessa perspectiva. Sob essa visão, as lógicas de trabalho e as motivações do consumo se dão por uma escalada hierarquizada rumo ao topo das classes sociais vigentes em uma sociedade. Conquanto ainda hoje exerça influência empírica, questionamentos sobre a amplitude dessa visão colocaram em cheque as metodologias que se valem estritamente da hierarquia de Maslow.

Doutra sorte, sob o aspecto da antropologia do consumo, a lógica do consumo se opera por meio daqueles padrões simbólicos de escolhas e significações, como apresentados por Douglas e Isherwood.

Nesse sentido, a conjuntura cultural contemporânea apresenta rica possibilidade de análise das lógicas de consumo sob a perspectiva antropológica, especialmente dentro de culturas hibridizadas. De nenhuma forma esse tópico se opõe ou menospreza a visão de Maslow quanto à hierarquia das necessidades, o que se propõe, todavia, é apresentar aspectos culturais da contemporaneidade que sugerem a necessidade de uma visão mais relacional, dinâmica e adaptável sobre a cultura dos grupos sociais em questão.

A cultura híbrida inserida nos grupos sociais conduz seus indivíduos a praticar ideologias reificadoras da ordem social do próprio grupo. São, portanto, ideologias que influenciam as diversas escolhas materiais e/ou simbólicas dos indivíduos e, consequentemente, as lógicas de consumo desse grupo.
As culturas híbridas oferecem, além da própria hibridização cultural, hibridizações de escolhas e dinâmicas próprias de consumo. Sendo o consumo uma prática antropologicamente interpretada como um evento ritualístico (DOUGLAS; ISHERWOOD, 2004), culturas híbridas gestam, por conseguinte, dinâmicas híbridas de consumo.

A economia simbólica vigente dentro da comunidade deverá guiar a lógica de consumo dos indivíduos desse grupo. Uma ótica bourdiana do consumo pode dialogar com a percepção antropológica. A ordem dentro do grupo social será mantida pelo poder simbólico exercido e legitimado dentro do próprio grupo. O consumo, portanto, oferece uma gama de signos e significações no sentido de fortalecer essa percepção simbólica e legitimadora sobre a existência de funções sociais e status do próprio grupo.

A heterogeneidade cultural imanente das culturas híbridas mescla, legitima e adapta novas lógicas de consumo. Um exemplo do consumo a partir das culturas híbridas é descrito por Maria Antunes Calil em sua etnografia do Nation Disco Club. O Nation Disco Club era uma casa noturna que tocava os hits mais populares e modernos em música eletrônica dos anos 1980 na grande São Paulo. Na maior parte do tempo, foi palco da mais atual casa de house music do Brasil para aquela época.

O Nation foi uma mescla de clube noturno com espaço para lazer, conversas informais e várias formas de sociabilidade. Apresentava proposta diferente para a época, uma vez que mesclava um ambiente inovador e descontraído com locais para leitura, bate-papo e mesmo um relaxamento informal. A casa disponibilizava ainda revistas nacionais e internacionais sobre moda, música e cinema, além de realizar desfiles de moda em algumas ocasiões.

Calil (1996, p. 215) descreve em sua etnografia que "as tais atualidades da área da arte, da moda, as literárias e as músicas do mundo pop" eram o assunto mais cotado. Os frequentadores da casa demonstravam viver a lógica dos neodândis (apelido dos freqüentadores) continuamente, mesmo fora da Nation em seu trabalho, estudos e/ou família.

A autora indica que os frequentadores observavam estritamente rituais de consumo simbólico sobre moda, estética (especialmente relacionados a cortes de cabelo extravagantes, brincos, correntes, 
pulseiras e colares), revistas sobre temas que circulavam no ambiente e principalmente discos das músicas que eram tocadas.

\section{Calil relata que:}

as roupas e os acessórios de brechó, pelo estranhamento (peças de época), pela diversidade de temas de inspiração (das mais variadas origens) e pelas "festas de década" que o Nation promoveu, se tornaram muito valorizadas (CALIL, 1996, p. 220).

A cultura híbrida que se formou a partir do clube promoveu o consumo de variados bens. Anseios por pertencimento a signos de atração de parceiros, respeito, popularidade, entre outros fatores viam no consumo o veículo para sua realização.

O relato do Nation Club e dos neodândis dos anos 1980, em São Paulo, são retratos de novas lógicas de consumo em função de novos movimentos culturais.

Como afirma Geertz (1989, p. 27), “deve-se atentar para o comportamento, e como exatidão, pois é pelo fluxo do comportamento - ou, mais precisamente, da ação social - que as formas culturais encontram articulação". Esse comportamento que articula determinada forma cultural é percebido na etnografia do Clube pela nova dinâmica de consumo.

$\mathrm{O}$ consumo dos frequentadores legitimava e articulava a cultura híbrida gestada no Nation Club, ao mesmo tempo em que eram dinamicamente mesclados com diversas influências transfronteiriças, tanto dos hits que vinham diretamente de Chicago para São Paulo como das mesclas entre pequenas tribos urbanas que compartilhavam da mesma ritualista em dançar, beber, usar algumas drogas, mandar acenos de mãos em código, usar roupas excêntricas ou conversas sobre assuntos descolados.

O consumo desses indivíduos pode ser interpretado antropologicamente como prática cultural daquela comunidade urbana, substrato da hibridização cultural, o que não restringe, porém, a existência de outras lógicas simbólicas de hierarquização a partir do consumo ou de outros interesses.

Implica ressaltar que a antropologia do consumo vê a sociedade como comunidade social e cultural, não limitada a uma estrutura de classes, porém de forma hierarquizada. Essa hierarquia é simbólica, assim como a prática que positiva sua existência. Está mais relacionada a status social e aceitação pela comunidade do que emancipação social de um siste- ma opressivo (conquanto não exclui essa possibilidade, foca o olhar em um aspecto cultural).

Essa heterogeneidade multifuncional a que Canclini chama de culturas híbridas demonstra abrir caminho para novas percepções acerca das práticas de consumo. O olhar antropológico permite, pelas suas descrições densas, observar o consumo pela ótica do próprio ator, qual seja uma interpretação sobre o interpretado pelo atuante no cenário.

O "trabalho de campo etnográfico" (MALINOWSKI, 1998, p. 18) é, portanto, a ferramenta chave para a compreensão da lógica do consumo pela interpretação do próprio consumidor. Uma ficção da ficção, como afirma Geertz (1989), não obstante o valor científico da descrição.

Ao passo que Evans-Pritchard (1978, p. 20) afirmou nas páginas iniciais de sua clássica etnografia em Nuer: "da porta da minha barraca podia ver o que acontecia no acampamento ou aldeia", a antropologia do consumo demanda que o etnógrafo saia para além da porta de sua barraca acadêmica e geográfica e se insira no lócus da cultura híbrida para viver e presenciar a dinâmica do consumo que se processa no grupo.

Interpretando o consumo por uma visão dos eventos sociais dentro da própria cultura, o olhar antropológico permite enxergar além, onde a simples observação casual ou mesmo a observação técnica não lograriam.

\section{Considerações finais}

Este artigo procurou construir, por intermédio de revisão bibliográfica, diálogo entre as percepções sobre o reconhecimento dado pela hibridização das culturas como apresentado por Nestor Canclini (2000) e o consumo considerando um olhar de vertente antropológica. Para além das razões antropocêntricas e histórico-lineares do consumo, procurou-se apontar alguns caminhos na lógica que o consumo traça dentro dessas culturas híbridas.

Novas ideologias e culturas fortalecem novas práticas sociais e novas dinâmicas de consumo. Nesse sentido, a antropologia concebe captar o despercebido, acostumar-se ao estranho, revelando-o dentro daquilo que é ordinário no cotidiano da comunidade de consumidores; isso a partir do indivíduo e membro do grupo cultural investigado. 
Um olhar exaustivo que, de dentro para fora do grupo, percebe o usual como distinto e o comum como diferente.

Nesse sentido, as culturas híbridas demandam um olhar flexível, adaptável e desvelador do diversificado que gera as novas lógicas e significados de consumo. Tarefa apropriada para a etnografia, que, certamente, tem se defrontado com novas problemáticas da contemporaneidade e profícuas para ricos trabalhos de campo.

\section{Referências}

BARROS, C. P. Hierarquia, escassez e abundância materiais: um estudo etnográfico no universo de consumo das empregadas domésticas. In: MIGUELES, C. (Org.). Antropologia do consumo: casos brasileiros. Rio de Janeiro: Editora FGV, 2007.

BAUDRILLARD, J. A sociedade do consumo. Lisboa: Edições 70, 1995.

BOURDIEU, P. A economia dos bens simbólicos. In: Razões práticas. Campinas: Papirus, 1996.

"Sobre o poder simbólico". In: O poder simbólico. Lisboa: DIFEL, 1989.

CALIL, M. A. O retrato do Nation Disco Club: os neodândis no final dos anos 80. In: MAGNANI, J. G. C; TORRES, L. L. Na metrópole: textos de antropologia urbana. São Paulo: Editora da Universidade de São Paulo, 1996.

CANCLINI, N. G. Culturas híbridas, poderes oblíquos. In: Culturas hibridas: estratégias para entrar e sair da modernidade. 3. ed. São Paulo: Editora da Universidade de São Paulo, 2000.

DOUGLAS, M.; ISHERWOOD, B. O mundo dos bens: para uma antropologia do consumo. Rio de Janeiro: Editora UFRJ, 2004.

EVANS-PRITCHARD, E. E. Antropologia social. São Paulo: Martins Fontes, 1978.

Os Nuer. São Paulo: Perspectiva, 1978.

GEERTZ, C. A interpretação das culturas. Rio de Janeiro: Livros Técnicos e Científicos Editora: 1989.

HALL, S. Significação, representação e ideologia: Althusser e os debates pós-estruturalistas. In: HALL, S. Da diáspora: identidades e mediações culturais. Belo Horizonte: Editora UFMG, 2009.

LEITÃO, D. O mundo dos bens: para uma antropologia do consumo. Disponível em: <http://www.antropologia.com.br/ res/res20.htm>. Acesso em: junho 2011.
LEVI-STRAUSS, C. A crise moderna da antropologia. In: Revista de Antropologia. v. 10, n. 1/2, julho/dezembro 1962.

MAGNANI, J. G. C; TORRES, L. L. Na metrópole: textos de antropologia urbana. São Paulo: Editora da Universidade de São Paulo, 1996.

MALINOWSKI, B. Os argonautas do Pacífico ocidental: um relato do empreendimento e da aventura dos nativos nos arquipélagos da Nova Guiné melanésia. São Paulo: Abril Cultural, 1998.

MASLOW, A. H. Uma teoria da motivação humana. In: BALCÃO, Y.; CORDEIRO, L. L. (Org.). O comportamento humano na empresa. Rio de Janeiro: FGV, 1975.

SANTOS, M. O país distorcido: o Brasil, a globalização e a cidadania. São Paulo: Publifolha, 2002.

Recebido em: 19 de abril de 2013 Aceito em: 12 de junho de 2013. 